\title{
EXPERIMENTAL RUPTURE OF THE MEDIAL COLLATERAL LIGAMENT OF THE KNEE
}

\author{
Ewen A. Jack, Edinburgh, Scotland
}

\begin{abstract}
Severe injuries to the ligaments of the knee joint have recently begun to attract attention as a promising field for early reparative surgery. Palmer (1938) rationalised the diagnosis of these injuries and described the technique of surgical repair. Since then several further contributions, mostly from abroad, have supported early operation. In Britain, to judge from the literature, most surgeons prefer conservative treatment in the form of prolonged immobilisation. Whichever method is advocated, healing seems to be taken for granted, despite the scantiness of our knowledge both of the precise effect of injury on ligamentous tissue and of its reparative power. This paper describes an investigation which has been undertaken to determine firstly, the anatomical result of rupture of a ligament, and secondly, the response in the ligament to repair the damage. From this information it was hoped to obtain evidence for or against early operative repair.
\end{abstract}

\section{EXPERIMENTAL METHOD}

Experiments were carried out on the medial collateral ligament of the knee joint of the cat. This is very similar anatomically to its human counterpart, and the vascular pattern, as determined by indian ink injections, is almost identical.

Under anaesthesia the ligament was ruptured by forcible abduction of the extended knee over the edge of the operating table. The medial side of the knee joint was immediately explored to determine the exact nature of the injury to the ligament and surrounding tissues. Displaced tissue in most cases was smoothed back into place but was not sutured; in a few cases displacement was allowed to persist. The wound was closed, but the limb was not immobilised. At varying intervals after rupture, the knees were re-explored, the naked eye appearance of the damaged area was determined and the ligaments were removed for microscopic examination. The animals were then killed.

\section{PATHOLOGICAL ANATOMY}

Normal ligament is composed of dense, relatively acellular and regular collagen tissue. The fibres are arranged in parallel longitudinal bundles separated by scanty areolar tissue, just sufficient to allow slight gliding movement between the bundles and to transmit the very sparse capillary vessels which run longitudinally through the substance (Fig. 1). The medial ligament is invested superficially by a thick layer of loose areolar tissue which covers the joint capsule and forms an incomplete sheath for the ligament. This tissue is very vascular, and from it small vessels enter the ligament. The deep surface of the ligament lies in relation to the synovial reflections above and below the meniscus, from which a small subsidiary blood supply is derived by the deep fibres, particularly in the upper segment. No vessels enter through the bony attachments. Elastic fibres are absent from the ligament itself, but are found in the loose areolar covering.

Rupture of the medial ligament was produced in nineteen experiments. In every instance the long band ruptured along a definite line without detachment of bone flakes. The tears occurred close to the lower attachment six times and at the upper attachment seven times. In the remaining six cases an oblique tear involved the whole length, leaving two long triangular tongues of ligament. Stretching or rupture of fibres at many different levels has been 
described but was not seen. In several of the long oblique tears the impression of stretching was given at first sight, because the loose areolar covering remained intact and continued to contain the fragments of ligament. But when the covering layers were divided and the ligament was exposed, the complete rupture was always discovered.

The ends of the ligament always recoiled. When the tear was oblique the two parts recoiled towards the attachments, but remained in contact with one another because of the nature of the rupture. In the transverse tears a wide gap was frequently found (Fig. 2). The body of the ligament was usually tortuous and curled up under the areolar sheath. Fibre bundles were disrupted and frayed, and microscopically the individual fibres assumed a fine wavy appearance in contrast with normal ligament collagen (Fig. 3). These changes often involved the whole length of the ligament. Associated damage to the joint capsule was variable, and was least in the lower end ruptures. When the upper end of the ligament parted, it was found to be torn away from the capsule on one or both sides down to the level of the joint, where the tear frequently involved the synovial membrane above the meniscus and laid the joint open.

Displacement of the ends of the ligament is obviously important in influencing healing. It is probably caused by momentary persistence of the abduction violence which ruptures the ligament so that the ends are separated inside the elastic areolar covering. This then grips the fragments and prevents them from falling back into place when the joint resumes a normal position. Immediately after the injury replacement of the tissue without undue

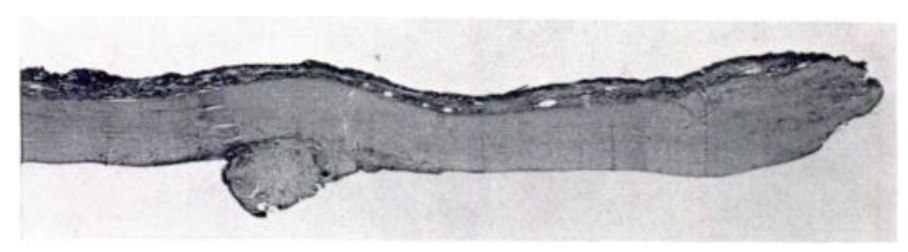

FIG. 1

Normal medial collateral ligament of the knee joint of a cat. Low power $\left(\times 4 \frac{1}{1}\right)$, showing upper half of ligament.

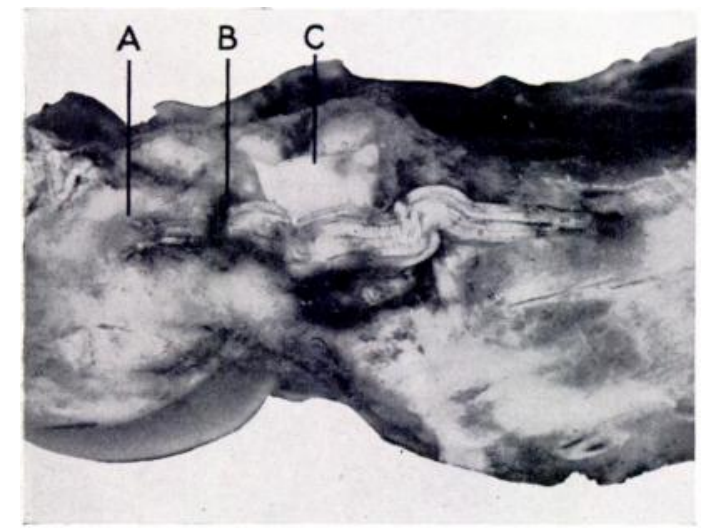

IiIg. 2

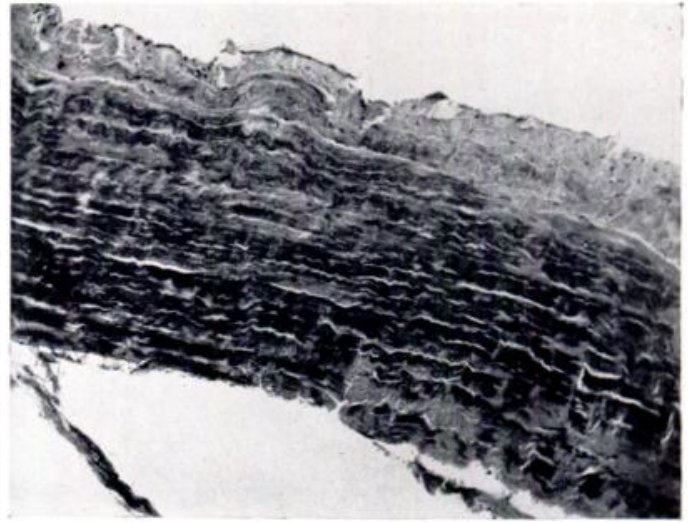

FIG. 3

Figure 2-Rupture of a ligament at the upper attachment $(\times 11)$. Dissection was performed after fixation in formalin immediately after injury. The original attachment is seen at $A$ with a tiny strand still attached; $B$ indicates the stump of the ligament which has recoiled almost to the level of the meniscus; curling and disruption of bundles are well shown; $C$ marks the semi-membranosus tendon. Figure 3-Section remote from the rupture shows the widespread disruption and the fine wavy appearance of the collagen bundles $(\because 75)$.

vol. 32 B, No. 3, AUgust 1950 
tension is easy because of the inelastic nature of the tissue, but in seven to ten dav's the retracted ligament shrinks and the tissue becomes oedematous and friable. Curling disappears and the individual fibres lose their fine wavy appearance. It is no longer possible to close the gap accurately and sutures will not hold. There is, therefore, only a brief opportunity for performing satisfactory surgical repair.

\section{THE PROCESS OF HEALING}

When conditions were favourable, the torn ligaments healed in the manner described in detail by Mason and Shearon (1932) in their studies of tendon injuries. Ligamentous tissue is almost identical with that of tendon, but the physical effects of injury are much greater in the former. The rupture gap fills with blood. Proliferation of cells from the loose areolar tissue quickly converts the clot into granulation tissue supporting the torn ends of the ligament (Fig. 4). At the same time an intense cellular reaction begins in the previously almost acellular tissue of the ligament, and blood vessels, hitherto almost unseen, become numerous. This cellular and vascular reaction may affect the whole length of the ligament.

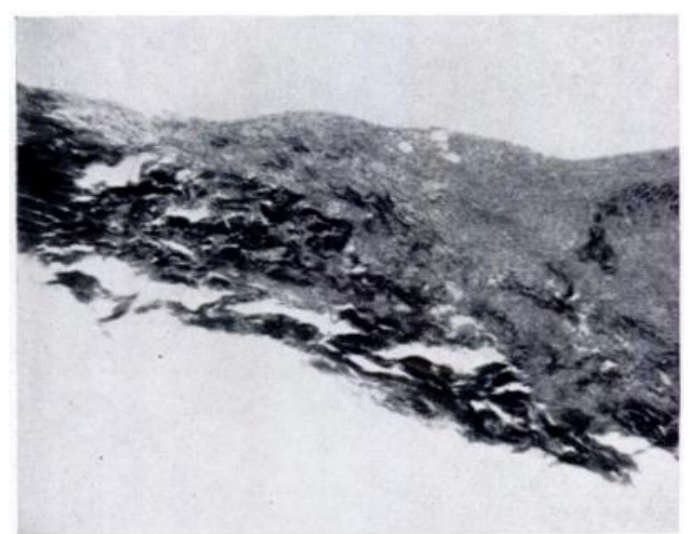

FIG. 4

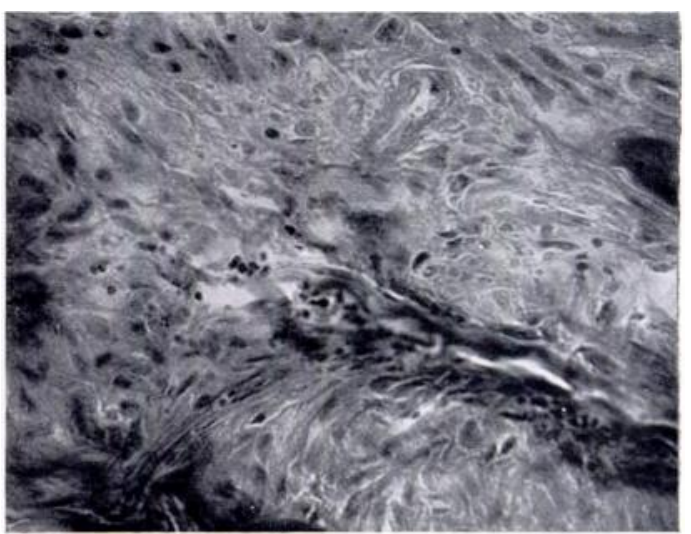

Fig. 5

Lower end tear seven days after injury. Figure 4-The tissue has broken under the microtome. (iranulation tissue fills the zone of rupture $(\times 40)$. Figure 5-Early multiplication of ligament cells and budding of collagen fibrils from a strand of ligament suspended in granulation tissue $(\times 300)$.

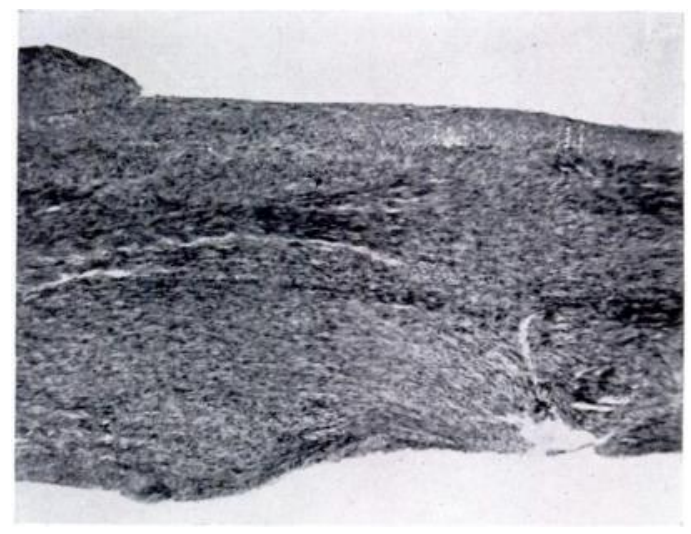

FIG. 6

Oblique tear fourteen days after injury $(\times 40)$. Intense cellular and vascular reaction is seen in the ligament. Leashes of new collagen fibrils with regular longitudinal orientation bridge the gap. 
After four or five days, proliferation of the ligament cells begins with the formation of fine new collagen fibrils (Fig. 5). Cells and fibrils migrate from the torn ends into the granulation tissue until the gap is bridged by collagen tissue, which quickly assumes a regular longitudinal arrangement. After two weeks the granulation tissue is replaced by well-dereloped parallel collagen fibres of immature trpe, continuous with the original ligament fibres, and the torn ends can no longer be distinguished (Figs. 6 and 7 ). After three weeks there is good tensile strength, and little abnormal lateral mobility can be demonstrated. Thereafter cells and blood ressels gradually diminish in number, while collagen fibres increase in size and strength and begin to assume arrangement into bundles. Thickening of the areolar tissue covering subsides, and the tissue separates into layers (Fig. 8). Within seren to eight weeks the ligament appears virtually normal to the naked eve except for slight local thickening and possibly some surface adhesions. Microscopically an increase in cells and blood ressels is noted for many weeks after injury (Fig. 9).

This process represents healing by regeneration of regular collagen tissue from the ligament fibres so that continuity and an almost normal state are restored. It was found in

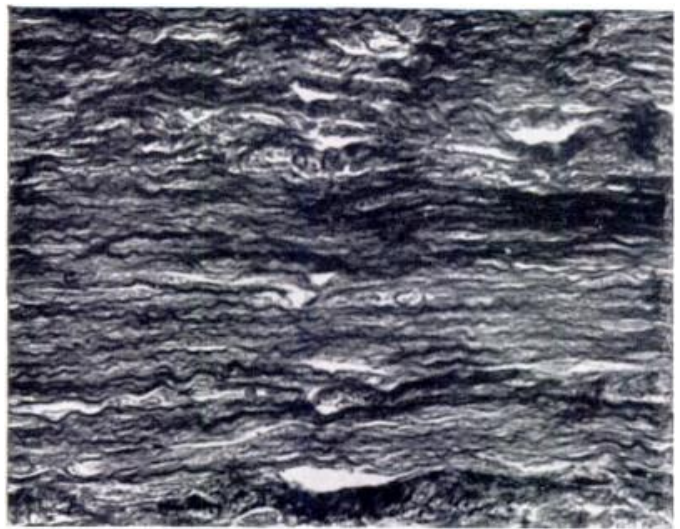

FIG. 7

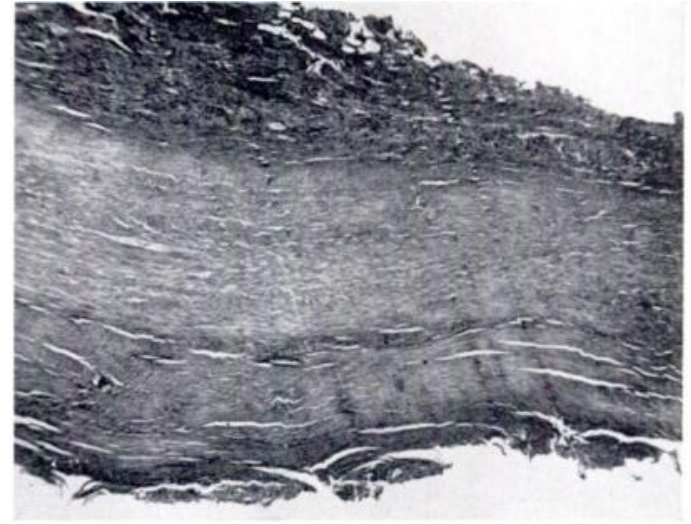

Fig. 8

Figure 7 -Oblique tear seventeen days after injury $(-300)$. The miniature young fibrils can be seen. The termination of the original ends of the ligament can no longer be distinguished. Figure 8-Lower end tear fort $y$-nine davs after injur $(40)$. The areolar tissue is still thickened but is separated intolavers again. The rupture has healed by regeneration of regular collagen tissue which is beginning to approach normal. Cells and capillaries are still numerous.

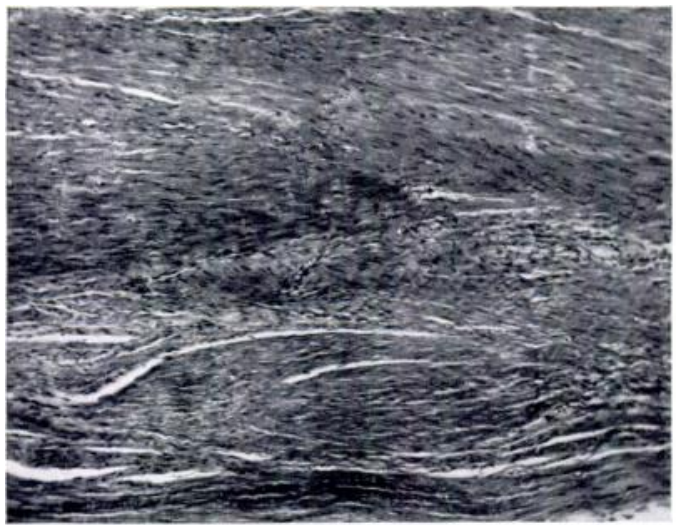

FIG. 9

Oblique tear sixty-three days after injury $(\times 75)$. Cells and ressels are still very numerous. The collagen tissue is mainly well orientated and is beginning to separate into bundles.

vol. $32 \mathrm{~B}$, No. 3 , AUGUST 1950 


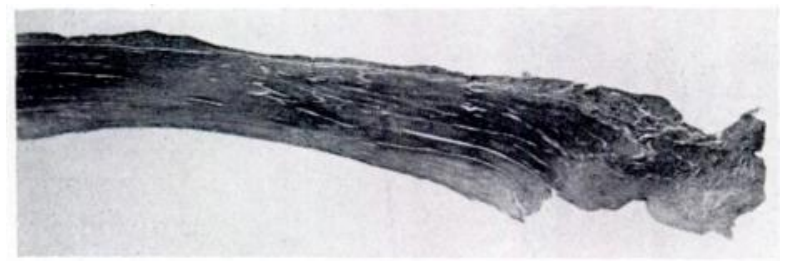

FIG 10

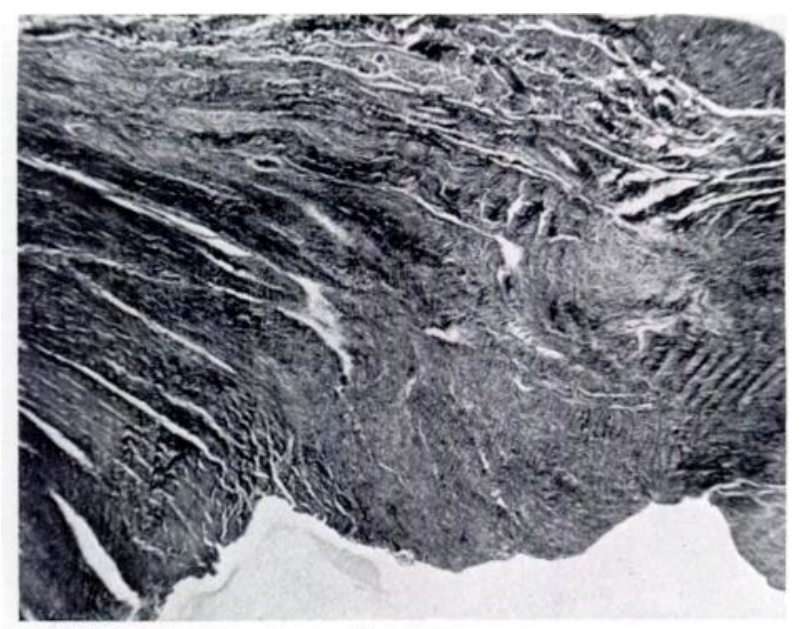

Fig. 11

Upper end tear 147 days after injury. Figure 10-The upper attachment of the ligament has curled in preparation of the specimen $(\times \mathbf{4})$. It is represented by a mass of scar tissue in which the retracted end of the ligament ends abruptly. Figure 11 - The stump of ligament ends in an irregular scar which has filled the gap. There has been no attempt at regeneration from the end of the torn ligament which can still be clearly recognised $(\times 45)$.

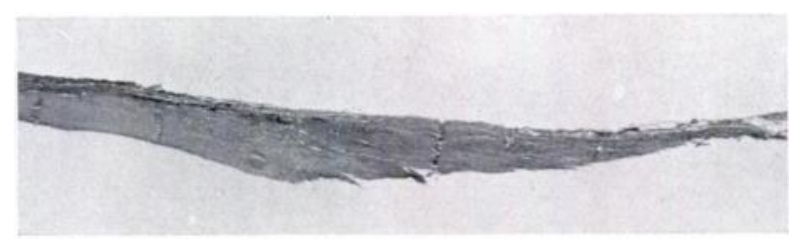

FIG. 12

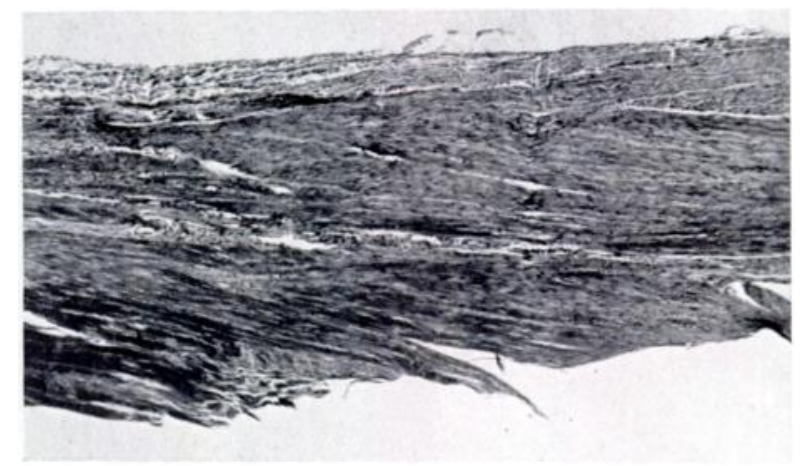

FIG. 13

Upper end tear seventy days after injury. Figure 12-The greatly elongated attachment to the femoral condyle is well shown $(\times 41)$. Compare the attachment of the normal ligament in Figure 1. Figure 13-The long gap has been bridged by new collagen fibres with regular longitudinal orientation. These arise from the superficial part of the ligament. The deep fibres are deeply stained and quite inactive in contrast with the regenerated zone in which cells and vessels are still numerous $(\times \mathbf{4 5})$ 
every case of oblique rupture in which the overlapping ligament fragments remained in close approximation. It was also noted in all but one of the lower end ruptures. The one failure was in a case in which wide displacement of the ligament was allowed to persist at the original exploration. Examination after two weeks disclosed a large organising haematoma between the torn ends, in which the ligament fibres became lost. Displacement of the tissue was the obvious cause of failure.

The group of upper end ruptures presented a very different picture. Five were examined at an interval of three weeks or more after injury; four of these had healed by formation of diffuse irregular scar tissue devoid of orderly arrangement. Of the four cases, one was similar to the single failure noted in the lower end ruptures; wide displacement was allowed to persist and the ligament tissue became lost in a mass of irregular scar. The remaining three showed similar characteristics. A moderate gap was filled with irregular scar in which the ligament stump terminated abruptly (Fig. 10). The normal cellular and vascular reaction to the injury was seen in the lower part of the ligament, but in the part adjacent to the rupture it was remarkable for its absence (Fig. 11). The tissue appeared quite inert, and vacuolation in the few cells seen suggested that it was undergoing ischaemic necrosis. One case only showed any attempt at healing by regeneration of regular collagen tissue. Here a long gap was found to be bridged by longitudinally arranged new fibres which arose from the superficial half of the ligament. The deep half of the original ligament was inactive and devoid of cells and vessels (Figs. 12 and 13).
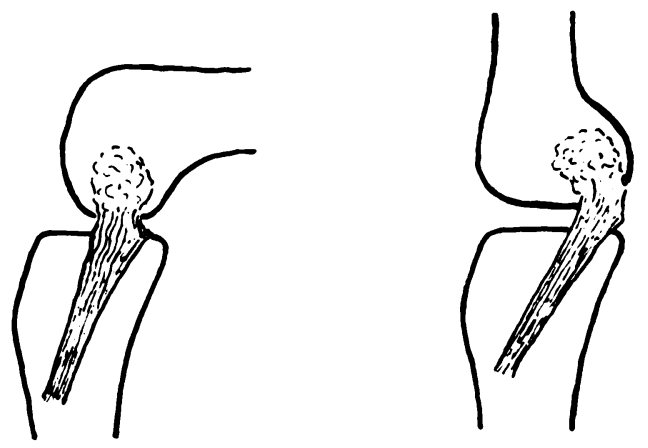

FIG. 14

Diagram to show the effect of adhesion of the ligament to the femoral condyle, the adhesion having occurred in the position of flexion. When the knee is extended, the whole ligament moves back with the femoral attachment.

This high incidence of failure of regeneration in upper end ruptures may have been due in part to persistent displacement of tissue. A tear at the upper attachment is much more likely to be affected by movement of the knee after injury, because the upper end of the ligament is the "working" end about which the femur rotates. In every case of upper end rupture the upper part of the ligament from the level of the meniscus to the normal attachment was represented macroscopically by a mass of scar tissue adherent to surrounding tissues and to the femoral condyle over a long area. The scar anchored the upper third of the ligament to the femoral condyle, so that when the knee was flexed and extended the ligament rotated with the femur (Fig. 14). The scar had little tensile strength, and it was possible to demonstrate lateral rock long after injury. But there can be little doubt that the main reason for failure of regeneration in upper end ruptures is interference with the blood supply to the torn end of the ligament caused by disruption of the ligament bundles and by the associated injury to the areolar covering and synovial membrane from which the blood supply is derived.

vol. $32 \mathrm{~B}$, No. 3, AUGUST 1950 


\section{GONCLUSIONS}

Rupture of a ligament usually occurs along a definite line, but is associated with considerable intrinsic damage to the remote parts of the ligament. In spite of this, healing occurs by regeneration of regular collagen to form a new ligament with good tensile strength, provided the ends of the torn ligament are in reasonable apposition, and provided the blood supply is adequate.

When lateral instability of the knee after a recent injury suggests that a collateral ligament has been ruptured, wide displacement of the torn ends should be suspected. Accurate replacement can be guaranteed only by surgical intervention; operative repair therefore seems to be justifiable on anatomical grounds. If operation is contemplated it should be undertaken within the first week after injury when it is easy to achieve accurate repair, which later becomes impossible because of shrinkage and friability of the tissue. In order to preserve blood supply, the areolar covering should be disturbed as little as possible, and the least possible amount of fine suture material should be used to anchor the torn ends in position. Nevertheless when the tear involves the upper attachment, ischaemia of the damaged ligament may prevent normal healing, whatever the treatment adopted.

This paper is an abridged version of part of a thesis submitted to the University of Edinburgh for the degree of Master of Surgery. The author received a part-time grant from the Medical Research Council while the experimental work was in progress. This was performed in the Wilkie Research Laboratory under the direction of Sir James Learmonth, to whom full acknowledgement is made for every assistance.

\section{REFERENCES}

Mason, M. L., and Shearon, C. G. (1932): The Process of Tendon Repair. Archives of Surgery, 25, 615. Palmer, I. (1938): On the Injuries to the Ligaments of the Knee Joint. Acta Chirurgica Scandinavica, 81, supplement $\mathbf{5 3}, 3$. 